OPEN ACCESS

Edited by:

Ming Kuo,

University of Illinois a Urbana-Champaign, United States

Reviewed by:

Mats Granlund,

Jönköping University, Sweden Martha Monroe, University of Florida, United States

*Correspondence: Rachel Szczytko rachel.szczytko@gmail.com

Specialty section This article was submitted to Educational Psychology, a section of the journal Frontiers in Education

Received: 02 February 2018 Accepted: 31 May 2018 Published: 19 June 2018

Citation:

Szczytko R, Carrier SJ and

Stevenson KT (2018) Impacts of Outdoor Environmental Education on

Teacher Reports of Attention, Behavior, and Learning Outcomes for Students With Emotional, Cognitive, and Behavioral Disabilities. Front. Educ. 3:46.

doi: 10.3389/feduc.2018.00046

\section{Impacts of Outdoor Environmental Education on Teacher Reports of Attention, Behavior, and Learning Outcomes for Students With Emotional, Cognitive, and Behavioral Disabilities}

\author{
Rachel Szczytko ${ }^{1 *}$, Sarah J. Carrier ${ }^{2}$ and Kathryn T. Stevenson ${ }^{1}$ \\ ${ }^{1}$ Department of Parks, Recreation, and Tourism Management, College of Natural Resources, North Carolina State University, \\ Raleigh, NC, United States, ${ }^{2}$ Teacher Education and Learning Sciences, College of Education, North Carolina State \\ University, Raleigh, NC, United States
}

There are over 4 million students with reported emotional, cognitive, and behavioral disabilities (ECBD) in the United States. Teachers most frequently situate instruction inside, however, outdoor environmental education (EE) can improve academic and affective outcomes for many students, including students with ECBD. In North Carolina, U.S.A., an EE program utilizes outdoor science instruction for fifth-grade students. The program takes place over four to 10 full-school days across the year, and instruction occurs in both schoolyards and natural areas. The program aligns outdoor EE with state and national science education standards. Using a quasi-experimental design, the present study examined the impacts of the program on indicators of ECBD (e.g., student behavior, attention span), science efficacy, nature of science, and academic achievement for students with ECBD. We measured these factors using online surveys from both students identified with ECBD and their classroom teachers, as well as students with ECBD from matched control schools and their respective teachers. Students in both treatment $(n=99)$ and control $(n=62)$ classrooms took the survey two times over the school year. Quantitative data revealed teachers perceived students had significantly improved attention spans and decreased disruptive behaviors when learning outdoors. Students in the treatment group maintained measures of nature of science, science efficacy and science grades, keeping in line with their peers in the control group. We supplemented survey data with teacher interview data about their impressions of the outdoor program and the experiences of their students identified with ECBD. Teacher interview responses supported quantitative findings. These findings indicate that outdoor EE has the potential to be at least as effective a method for science instruction as classroom teaching, and in the case of addressing indicators of ECBD, outdoor EE may be a successful strategy for student learning.

Keywords: environmental education, attention, behavior, classroom, schoolyard, learning impairment, disability 


\section{INTRODUCTION}

Throughout the United States, there are 4 million public school students (i.e., 18 and under) identified with emotional, cognitive, and behavioral disabilities (ECBD) (National Center for Education Statistics, 2017). The phrasing "emotional/behavioral/learning disability" under the Individuals with Disabilities Education Act (IDEA) (108th Congress, 2004) includes students with a variety of emotional, behavioral, and cognitive impairments-such as Attention Deficit Hyperactivity Disorder (ADHD), autism, and dyslexia. While the number of students identified as ECBD in the United States has been on the rise since the 1970s (National Center for Education Statistics, 2017), there have been variable efforts among states and school districts, both in terms of funding and training, to better assist these students (Baker et al., 2012, 2017; Alexander et al., 2015). However, these students consistently lag behind their non-ECBD peers academically (Cawley et al., 2002). This points to the need for creative ways to assist students who have been identified with emotional, behavioral, or cognitive disabilities, through reducing ECBD students' challenges and increasing learning outcomes.

One such creative way to reduce ECBD students' challenges to learning includes time in the outdoors. Benefits of outdoor experiences have been explored most deeply in research on students with ADHD. Kuo and Faber Taylor, in particular, have researched this topic and have found green space to be highly beneficial for students identified with ADHD (Kuo and Faber Taylor, 2004; Faber Taylor and Kuo, 2011). In a 2004 nationwide study that collected parent ratings of their children's experiences in green outdoor settings, researchers found that playing in green spaces significantly reduced symptoms of ADHD for youth of all income levels, locations, and community types (Kuo and Faber Taylor, 2004). In a similar study, Faber Taylor and Kuo (2011) also found that for children with Attention Deficit Disorder (ADD) and/or ADHD, their attention spans improved when they participated in routine play (i.e., majority of days in the week) in green spaces. Furthermore, playing in open green spaces (e.g., fields) was more successful in reducing hyperactivity for students with ADHD than playing indoors or in built outdoor environments. Other researchers have found similar effects: green space near homes and schools is associated with improved concentration, better attention, and less hyperactivity among children (Wells, 2000; Mårtensson et al., 2009; Van den Berg and van den Berg, 2011; Amoly et al., 2014; Flouri et al., 2014; Markevych et al., 2014; Kuo et al., 2018). Other research has revealed the benefits of the outdoors for individuals with other forms of EBCD. For instance, Farnham and Mutrie (2003) found that outdoor education significantly reduced anxiety and improved trust and group cohesion for a range of students with mild to moderate learning disabilities. Similarly, Melber and Brown (2008) reported on the benefits of informal education for students who receive special education services, ranging from learning disabilities to motor impairment. Melber (2004) emphasizes that science taught with hands-on, inquiry practices such as in the schoolyard, are especially accessible to students with disabilities.
Environmental education (EE) may be a particularly promising strategy for helping ECBD students, as it has potential to combine time outdoors with instructional practices shown to be effective with ECBD students. The United States' EPA (2018) defines environmental education (EE) as "a process that allows individuals to explore environmental issues, engage in problem solving, and take action to improve the environment" (para 1). EE is characterized by being inquiry-based, hands-on, experiential, and often, outdoors (Hanna, 1995; Crawford, 2000; Haney et al., 2007; Peterson, 2011; Ruiz-Gallardo et al., 2013; Zint et al., 2014)-which are all strategies that have been found to boost attitudes and learning among students with ECBD. In particular, the inquiry-based aspects of EE programming has been shown to improve learning outcomes for students with ECBD (Aydeniz et al., 2012; Kaldenberg et al., 2015). EE programs for children can range from a single lesson in school to residential-weeklong experiences; they can even span the entire school year (North American Association for Environmental Education, 2010). Because of this variety of both program type and length, EE is uniquely situated to be flexibly integrated into education to increase both outdoor time and hands-on, inquiry-based instruction for students in schools.

Outdoor EE that targets science instruction may be an especially effective approach for integrating EE into curriculum while decreasing indicators of ECBD. Outdoor EE can integrate well with science instruction through its authentic environment and direct interaction with the outdoors. Building on Brown et al.'s (1989) situated learning theory, students' learning can be enhanced by their engagement with topics such as ecosystems through direct interactions in the context of study (i.e., in the outdoors). Science instruction in US classrooms is rarely situated in the outdoors, despite the noted benefits in both cognitive and affective domains for students when they learn outside (Rickinson et al., 2004; Dyment, 2005; Carrier et al., 2013, 2014; Fägerstam and Blom, 2013; Rios and Brewer, 2014). Research on EE programming has found that science efficacy, science knowledge, and science achievement improve for all students after the experience (Tamir, 1991; Hiller and Kitsantas, 2014; Saribas et al., 2014; Dettweiler et al., 2015; Ardoin et al., 2017). Accordingly, outdoor EE may work to decrease indicators of ECBD (e.g., short attention spans and disruptive behaviors) as well as enhance learning, especially in science.

In our literature review, we located only two studies that have specifically examined how EE may be particularly helpful to students with ECBD. One such study focused on the effects of a garden-based learning program on students with disruptive behavior disorder in Spain. The year-long program had students working outside over half of their school hours and was purposefully hands-on and project-based. A 6-year analysis revealed that the intervention led to a significant decrease in dropout rates, a significant increase in classes passed, and an increase in overall behavior and attitude (RuizGallardo et al., 2013). In a study by Moore et al. (2016), experienced EE practitioners took a class of students on an experiential nature hike where they used technology to engage with the outdoors. Researchers conducted additional interviews and observations of two students with ADHD. The study revealed 
that the students with ADHD had positive, enriching learning experiences; teachers noted these students had greatly improved their participation when compared to their participation in the traditional classroom. Additionally, these students, who typically fell behind in academic achievement, scored as well as their peers on the environmental knowledge assessment after the program. While these studies reveal a possible connection between outdoor $\mathrm{EE}$ and improved learning and behavioral outcomes, neither involved a control group.

As few studies exist investigating the potential benefits of outdoor EE on students with ECBD and none include a control group, the purpose of this study was to examine the impacts of an outdoor environmental education program on students with ECBD, utilizing a quasi-experimental design. Specifically, we tested the impacts of an outdoor-and science-based EE program on both ECBD students' challenges to learning (behavior, attention span) and learning outcomes (science efficacy, nature of science, science academic achievement) during the 2016-2017 school year. We hypothesized that for students identified with ECBD, their participation in an EE program would: (1) result in teachers reporting longer attention spans and fewer disruptive behaviors in a classroom setting compared to a control group; (2) result in teachers reporting longer attention spans and fewer disruptive behaviors outdoors when compared to their attention and behavior in a classroom setting; and (3) increase learning outcomes (i.e., nature of science, science efficacy, and science academic achievement) for students in the treatment group as compared to a control group.

\section{METHODS}

\section{Sampling}

Our sample consisted of 161 fifth-grade students with ECBD in North Carolina, U.S.A. Students ages ranged from 9 to 12 years old, with a median age of 10 years old. We focused on fifth-grade students, since they are in the late stages of middle childhood (ages 6-12) and approaching adolescence (ages 12-18)-a critical period for developing ethical and ecological knowledge necessary for influencing environmental education outcomes, such as environmental engagement (Kellert, 1985). We sampled in two stages: teachers, then, students. Treatment group teachers were recruited through an environmental education program in the southeastern U.S. (28 teachers, 99 students). Control group teachers were randomly selected from a list of matched control schools in the same geographic area. Schools were matched by percent of free-reduced lunch, percent of students that were white, location (e.g., in the same district or an adjacent district), and by charter or traditional distinction. We then created a sample frame of schools associated with those matched schools and invited a random subset of teachers from those schools to participate. We contacted 263 teachers, and 63 teachers agreed to participate as control, representing a $24 \%$ response rate. As we contacted these teachers a few months in advance of the study, a subset dropped out of the study prior to the pretest due to switching grade levels, moving schools, retiring, or other reasons. Forty-two teachers participated in the pretest as a control. Teachers in both treatment and control groups were asked about students whose Individual Education Plans identify them as ECBD, and we included those students in this study. As we only included classes with teachers that that had identified students with ECBD, we had usable data from 14 teachers (associated with 62 students) in the control group and 28 teachers (associated with 99 students) in the treatment group. Although self-selection bias may exist among teachers, students should not be affected as students are assigned to teachers regardless of their environmental interests or attention and behavior. In order to establish that our sample was representative of the general student population in North Carolina, we compared our final sample of students $(n=112)$ with the North Carolina population of students with Individual Education Plans as a whole using $z$-tests for proportions of gender (i.e., male vs. female) and a binary indicator of ethnicity (i.e., white vs. nonwhite). We found no significant differences ( $p=0.55$ and $p=0.54$, respectively) (Russell, 2016). Of our sample, 33\% students were female, $50 \%$ identified as non-Hispanic white, $11 \%$ as black, $4 \%$ as Hispanic/Latino, 2\% as Asian/Pacific Islander, $13 \%$ as Native American, $16 \%$ as other, and 5\% identified with two or more races. There were no differences in distributions of gender, race, or socioeconomic status across treatment and control groups (Table 1). All students whose parents provided consent were included in the study.

\section{Treatment}

This study was part of a larger program evaluation for an environmental education program in the southeastern U.S.A. The EE program that took place over the course of the 2016-2017 school year focuses on experiential, outdoor science learning, environmental literacy, and connection to the natural world. Schools participate in the program 4 to 10 full school days throughout the school year with an average of six lessons spread across the school year (e.g., one per month). The program took place both in the schoolyard and nearby natural areas, like state parks. Assuming teachers followed state guidelines, students also received indoor instructional time on each of the related state standard topics for approximately four, 1-h weekly sessions, which last 4-6 weeks for each of the science standard's unit of study.

TABLE 1 | Demographic comparison of treatment and control groups.

\begin{tabular}{lccc}
\hline & Treatment & Control & $p$-value \\
\hline $\begin{array}{l}\text { GENDER } \\
\text { Male }\end{array}$ & $71.2 \%(57)$ & $56.3 \%(18)$ & 0.935 \\
Female & $28.8 \%(23)$ & $43.7 \%(14)$ & \\
RACE & & & 0.400 \\
White & $51.3 \%(41)$ & $46.9 \%(15)$ & \\
Non-white & $48.8 \%(39)$ & $53.1 \%(17)$ & 0.895 \\
ATTEND TITLE I & & & \\
Yes & $85.0 \%(68)$ & $93.7 \%(30)$ & \\
No & $15.0 \%(12)$ & $6.3 \%(2)$ & \\
\hline
\end{tabular}

Percentage of total students reported with actual number of students in parentheses. Two-sample t-test results reported. 
The EE program targets fifth-grade students and centers on essential state science standards for this grade level. The first lesson in the EE program is an introduction to outdoor learning. This introductory day highlights skills and safety procedures for outdoor learning, scientific tools and uses (e.g., compass, hand lens), and science practices. Subsequent lessons highlight North Carolina's science standards that address the following topics: terrestrial and aquatic ecosystems; weather; ecosystem interactions; forces and motion; inheritances and adaptation; living systems; and matter and energy (Department of Public Instruction, 2015). Teachers choose from these topics to correspond with their scheduled science program to best supplement classroom instruction. The lessons last $4-6 \mathrm{~h}$ and typically involve a hike, a hands-on science experiment, science journaling, nature exploration, and group reflection. Students are split into small groups (maximum 12 students) for each lesson, which are supervised by a chaperone (e.g., parent/guardian, teacher, principal) and taught by the EE program instructor. The EE program instructors are all trained in hands-on, inquiry-based techniques and standards-based science content. Classroom teachers typically rotate between small groups within or between lessons.

\section{Data Collection}

Teachers administered online surveys in school during fall 2016 and the winter and spring of 2017 . We provided each teacher with a survey protocol that they were asked to follow. This protocol had a script for providing instructions to students, information on helping students, and details on accessing and taking their own survey. In addition to surveys, we interviewed teachers to provide a rich picture of the students' EE experiences during the program. We measured students' science efficacy and the nature of science through a 14 -item student survey (Table 2), which drew on the S-STEM (Unfried et al., 2015) and NOSI-E (Peoples et al., 2013) instruments, respectively. Scales were edited to facilitate a shorter instrument and to better align with the EE program goals. We pilot tested the full evaluation in spring 2016 with 609 students and 31 teachers. Both scales were valid and reliable (Table 2 ).

Teachers reported on student behavior, attention span, and academic achievement in science through teacher surveys administered before and after the EE program. To compare data over time while maintaining anonymity, all students were given teacher-generated, anonymous ID numbers. Teachers then utilized these ID numbers when filling out their surveys. We asked all teachers to rate each student's attention span and disruptive behavior in their classroom at the beginning and end of the study period (before and after enrollment in the outdoor EE program for treatment teachers, respectively). In addition, we asked treatment teachers to rate each student's attention and disruptive behavior for the outdoor EE program, including their expectations of student attention and behavior in the program (pre-test) and observed attention and behavior in the program by the end of the year (post-test). Teachers characterized students' attention spans on each survey in a range from short (1) to long (5); and disruptive behaviors from frequent problems (1) to none (5). This method of rating student attention and behavior is common practice in elementary school classroomsespecially for required documentation for ECBD student records (Finn, 1993; Friend and Bursuck, 2002) —and has been used in numerous similar studies (Doucette, 2004; Kam et al., 2004; Kuo and Faber Taylor, 2004; McFarland et al., 2013; Amoly et al., 2014). We also asked teachers to report science achievement as traditional grades (e.g., A to F). Although rating this method likely allowed for variance among teachers (i.e., different teachers may assess the same student differently), our analysis focused on changes over time, which relied on the same teachers assessing the same students over the course of the year. Teacher data were checked for errors (e.g., reverse coding, non-numerical) by two independent researchers and cross-referenced with the teacher, if necessary.

To gain further information on teachers' impressions of the EE outdoor program and experiences for students in the program, we interviewed eight teachers who agreed to follow-up interviews in summer 2017. We recorded, transcribed, and coded teacher interviews to document their impressions of the outdoor EE program and its impact on their students, including students with ECBD, to enhance our understanding of the program experience for these students. Aliases were given to all teachers for the analysis and interpretation.

\section{Data Analysis}

We analyzed our data using Stata software, version 14.2. We relied on paired $t$-tests to compare changes over time within the treatment group and ANCOVA (analysis of covariance) between the treatment and control group, respectively. We used these tests because they allowed for a direct comparison of individual students between their pre- and post-tests. As each student was compared against him-or herself, students not taking either the pre- or post-test due to school absences on the day teachers administered the surveys were not included in the analysis. Because of this, our final sample comprised 112 students, 80 treatment students and 32 control students. We compared students taking only the pre- or post-test to the rest of the sample and found no differences in terms of outcome variables.

We originally included a covariate for both taking students outside and amount of time spent outside during the school year (apart from the treatment associated with this study). Fifty percent of control and $71 \%$ of treatment teachers reported that they took students outside during the school year. Both control and treatment teachers had similar rates of taking students outside (14 days per year and 12 days per year, respectively). As there was no relationship between these indicators of time spent outside during the school year and learning outcomes (attention, science achievement, etc.), we omitted this in the final analysis of our results.

\section{RESULTS}

\section{Quantitative Data}

Prior to attending the outdoor EE program, teachers reported moderate attention spans $(M=3.65, \mathrm{SD}=1.19)$ and low levels of disruptive behavior $(M=4.25, \mathrm{SD} 1.10)$ for their 
TABLE 2 | Item-level statistics for science efficacy and nature of science scales among students identified as ECBD $(n=112)$.

\begin{tabular}{|c|c|c|c|c|}
\hline Item Wording & Mean & SD & Cronbach's alpha & Factor loadings \\
\hline Science efficacy & & & 0.83 & \\
\hline I feel good about myself when I do science & 3.99 & 0.84 & 0.80 & 0.77 \\
\hline I might choose a career in science & 3.04 & 1.18 & 0.81 & 0.68 \\
\hline I like learning about science & 4.07 & 0.92 & 0.80 & 0.73 \\
\hline I think about science when I'm not at school & 3.23 & 1.27 & 0.81 & 0.68 \\
\hline Science is one of my favorite subjects & 3.73 & 1.24 & 0.81 & 0.71 \\
\hline In the future, I will be able to do more advanced science work & 3.52 & 1.22 & 0.81 & 0.70 \\
\hline $\begin{array}{l}\text { I talk to my family or friends outside of school about what l've learned } \\
\text { about science }\end{array}$ & 3.30 & 1.22 & 0.80 & 0.69 \\
\hline Nature of science & & & 0.76 & \\
\hline A good way to know if something is true is to do an experiment & 3.88 & 1.01 & 0.75 & 0.50 \\
\hline Experiments are used to see what happens in nature & 3.88 & 0.84 & 0.72 & 0.64 \\
\hline Science helps answer questions about how something works & 4.13 & 0.84 & 0.71 & 0.72 \\
\hline Scientists use what they found in the past to help explain their new findings & 3.94 & 0.93 & 0.72 & 0.70 \\
\hline Conclusions can change when new evidence is found & 3.85 & 0.92 & 0.70 & 0.75 \\
\hline Scientists create different types of experiments to answer their questions & 4.16 & 0.79 & 0.71 & 0.71 \\
\hline If we do the same experiment many times, we may get different results & 3.74 & 0.95 & 0.76 & 0.45 \\
\hline
\end{tabular}

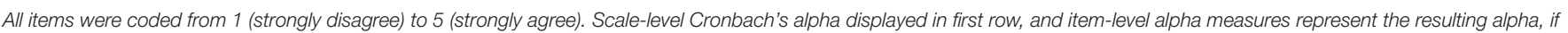
the item were removed. Factor loadings calculated through principle component analysis and verimax rotation.

students in the classroom, as well as moderately high science grades $(M=76.5 \%, S D=12.70)$. Among the treatment group, teachers expected shorter attention spans $(M=1.94, S D=2.29)$ and more disruptive behaviors $(M=1.81, S D=2.13)$ when students were learning outside. Student responses on the pretest indicated relatively high levels of science efficacy $(M=24.90$ out of 35, SD 5.98) and understanding of the nature of science $(M=27.57, S D=4.02)$. We found acceptable levels of reliability and validity for both the science efficacy and nature of science scales (Table 2). We also note that there were no significant differences in pre-test scores for all student-reported variables (science efficacy and nature of science) between treatment and control groups. However, teachers reported higher levels on every measure for the treatment group vs. the control group on the pre-test scores (attention: mean difference $=0.78, t=3.08$, $p=0.003$; behavior: mean difference $=0.62, t=2.56, p=0.01$; science grades: mean difference $=7.53, t=2.88, p=0.005$ ). This may reflect a difference among teachers in appraisal of their students. However, our analysis related to hypothesis testing compared within group changes, with the same teachers assessing the same students at the time of the pre- and post-test, which should mitigate any challenges comparing treatment and control groups.

We found support for hypotheses two, but not hypothesis one, as there were no differences in changes in teacher reports of classroom attention and behavior when comparing treatment and control groups [attention: $F_{(1,94)}=0.20, p=0.653$; behavior: $\left.F_{(1,94)}=0.04, p=0.845\right]$; however, teacher reports of students' attention and behavior levels when in the outdoor EE program improved over the course of the EE program to exceed classroom levels. Teacher reports of classroom attention and behavior remained stable for both the treatment and control groups, as there were no significant differences in pre- and post-scores for either measure in either group. However, among the treatment group, we found that teacher reports for both attention and behavior significantly improved for the outdoor EE program (Figure 1). Although prior to seeing students in the EE program teachers expected relatively short attention spans $(M=1.81$ out of $5, S D=2.13)$ and frequent disruptive behaviors $(M=$ 1.94 out of $5, S D=2.29$ ) outdoors, their appraisal of these measures was significantly higher (i.e., longer attention spans, improved behavior) at the end of the study period (attention: pre/post mean difference $=2.48, t=5.70, p=0.000$; behavior: pre/post mean difference $=2.55, t=5.50, p=0.000$ ). Further, both of these measures exceeded similar classroom levels at the time of the post-test in the treatment group (attention: outdoor/indoor mean difference $=0.54, t=5.23, p=0.000$; behavior: outdoor/indoor mean difference $=0.25, t=2.95$, $p=0.002$ ).

We found partial support for hypothesis three that the outdoor EE program significantly increased learning outcomes for students. Science efficacy and science grades remained the same over the study period for students in both the treatment and control groups (Figure 2). The nature of science significantly increased for students in the treatment group, while the understanding of nature of science for students in the control group stayed the same (treatment: pre/post mean difference $=$ $0.90, t=1.85, p=0.034$; control $=$ pre/post mean difference $=-0.22, t=-0.27, p=0.605)$. However, ANCOVA results detected no differences between treatment and control groups across any measure. Students with IEPs did not make significant gains in nature of science scores $\left[F_{(1,111)}=0.14, p=0.710\right]$ nor in teacher-reported academic achievement in science $\left[F_{(1,96)}=\right.$ $1.58, p=0.214]$. 


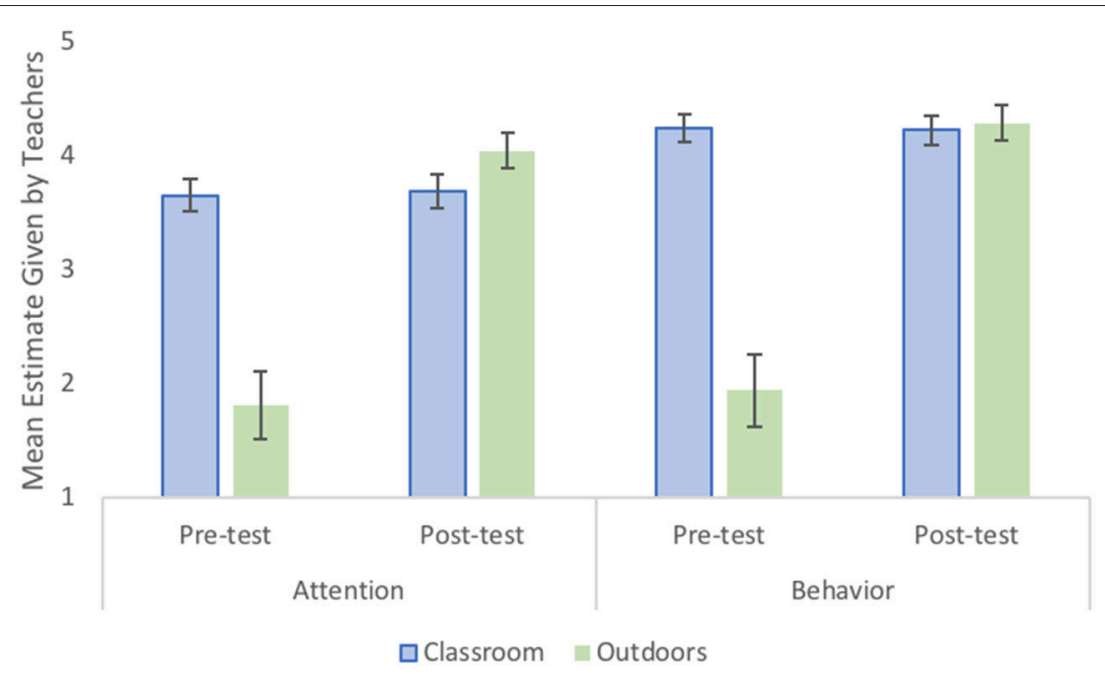

FIGURE 1 | Classroom and outdoor attention behavior among the treatment group. Teachers provided estimates of attention span and behavior levels from short (1) to long (5) and poor (1) to excellent (5), respectively. Error bars represent standard error. Paired $t$-tests indicate that differences between the teacher-reported pre- and post-test scores for attention and behavior while outdoors were significant (attention: $t=-5.70, p=0.000$; behavior: $t=-5.50, p=0.000$ ) as well as differences between the post-test scores in the classroom vs. outdoor settings (attention: $t=-5.23, p=0.000$; behavior: $t=-295$, $p=0.003$ ).

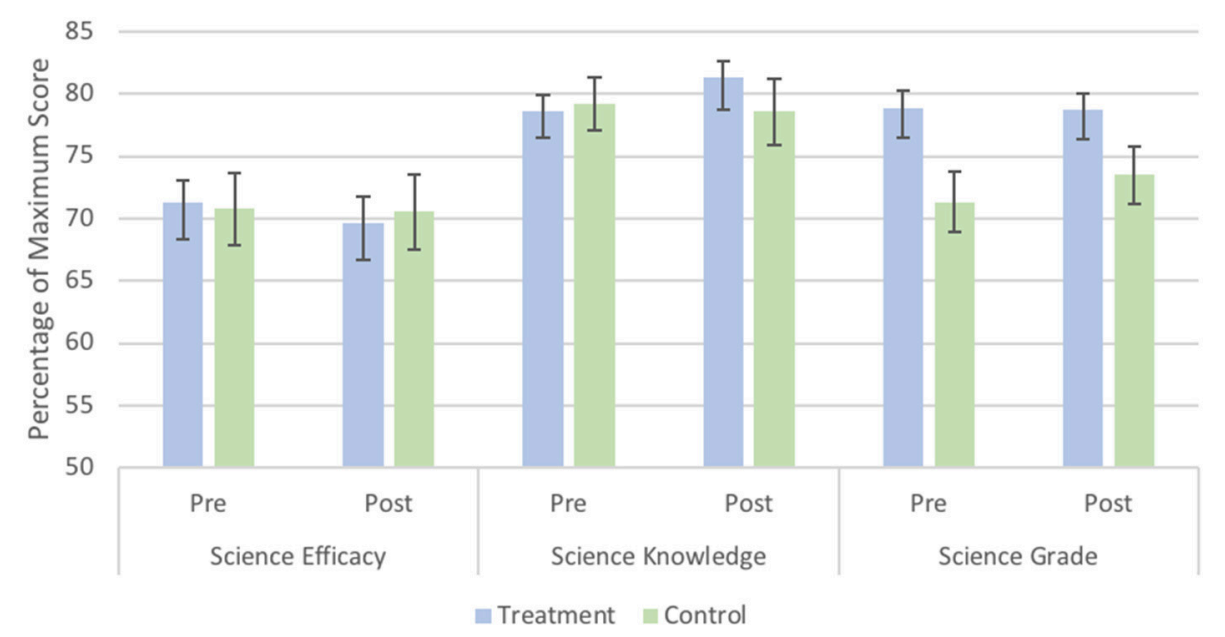

FIGURE 2 | Change in science efficacy, nature of science, and science grades among treatment and control groups. All measures are represented by percentages of the maximum score. Error bars represent standard errors.

\section{Qualitative Data}

Interview data about teachers' impressions of the outdoor EE program and experiences of their students with ECBD during the program are shown in Table 3. An overall theme that emerged from one teacher interview (Bailey) was the "value of getting kids outside more." Another teacher (Davis) elaborated saying, "Children just don't go outside anymore. My personal favorite thing is getting them outside and exposing them to doing something outside." In line with hypothesis two-participation in the outdoor EE program significantly decreases challenges to learning (i.e., disruptive behaviors and short attention span) - teachers saw students with ECBD become more engaged when learning outside: "They (students with
ECBD) were attentive and fully interacted with the activities. They felt they were successful which does not happen much in the regular classroom." Negative cases emerged as well. Some teachers reported obstacles to outdoor learning with the weather such as when was rainy or cold. Taylor described students' distress when they were asked to spend outdoor time writing in their journals rather than moving and exploring. When asked what part of the environmental education program students disliked, Taylor described students' initial complaints about physical activity that they clearly overcame. "The first couple of times when we were having to do all that walking...not being able to sit in front of something with a screen. They're used to passive learning but by the fourth time they were sad and crying that it's 
TABLE 3 | Emergent themes from interviews with teachers.

\begin{tabular}{|c|c|c|}
\hline Teacher & Theme-Outdoors & Theme-ECBD students \\
\hline Jessie & $\begin{array}{l}\text { You don't have to go really far away, just use what you have. Use what's in } \\
\text { our backyard... using the plants around you. }\end{array}$ & $\begin{array}{l}\text { Even (Students who) are really rough and tough, you would find them out } \\
\text { there playing with leaves and you know, just enjoying it. } \\
\text { (In describing reluctant student) She's not an outdoorsy type person, but } \\
\text { she just embraced it and enjoyed it when she gave it a trial. }\end{array}$ \\
\hline Bailey & $\begin{array}{l}\text { (in the outdoors) you can intertwine living systems, genetics, and body } \\
\text { systems... weather, terrestrial ecosystems, and then we always do aquatic } \\
\text { ecosystems. }\end{array}$ & $\begin{array}{l}\text { (ECBD students) so unique, full of energy and unique. They have their own } \\
\text { way of looking at the world, and when they got in that creek, it was just one } \\
\text { of the happiest moments. I mean they're all picking up rocks and looking at } \\
\text { them and so excited. } \\
\text { They were just loving it... you never know what lessons that they connect to } \\
\text {... definitely activities that connect well to different identities and groups. } \\
\text { (Instructors) work really hard to connect with each group. } \\
\text { Seems to be the easiest curriculum to teach. There's no science anxiety like } \\
\text { you hear about reading or math anxiety. }\end{array}$ \\
\hline Casey & $\begin{array}{l}\text { Just to appreciate and understand what's going on outside...I mean I love } \\
\text { that part of it. }\end{array}$ & $\begin{array}{l}\text { They make it a little not so scary for (ECBD students) who really don't like } \\
\text { (classroom) science. I think they make it at least more fun and more } \\
\text { interesting and engaging, and not so frightening. }\end{array}$ \\
\hline Davis & (Strongest features) integration of the science curriculum with the forest. & $\begin{array}{l}\text { They (ECBD) were attentive and fully interacted with the activities. They felt } \\
\text { they were successful which does not happen much in the regular classroom }\end{array}$ \\
\hline
\end{tabular}

over," thus emphasizing the impact of repeated, science-aligned experiences.

\section{DISCUSSION}

The present study adds to the literature on the impact of outdoor environmental education on students with ECBD utilizing a quasi-experimental, mixed methods design. Although past literature has supported a possible connection between outdoor $\mathrm{EE}$ and improved outcomes, in this study, we employed control groups to determine the potential of repeated, science-aligned, outdoor EE programming for improving student outcomes.

Our results related to students' attention and behavior suggest that teachers of ECBD students should consider the outdoors as a useful setting to increase attention and diminish disruptive behaviors. Although teachers expected students to have difficulty paying attention and avoiding disruptive behaviors outdoors, they reported longer attention spans and less disruptive behaviors outdoors for these students by the end of the year. We offer three possible explanations. First, teachers may have expected short attention spans and disruptive behaviors outdoors prior to the program and were pleasantly surprised from the first day outside onward. Secondly, teachers' perceptions of the behaviors themselves could have changed so that behaviors they previously considered disruptive (i.e., interrupting an instructor with a question) were considered as acceptable or indicative of high engagement. These two explanations are plausible in the context of prior research reporting that few teachers perceive the outdoors as an acceptable location for formal instruction beyond the preschool years (Ernst and Tornabene, 2012) and teachers in both United States and in the United Kingdom have concerns about student behavior and classroom management when teaching outdoors (Fox and Avramidis, 2003; Ernst, 2009). However, it is possible that teachers' expectations at the beginning of the study period aligned with actual student attention and behavior, and both measures did actually improve over the course of the outdoor sessions with more exposure to outdoor EE. This third explanation aligns with past research on the effects of green space on students with ECBD, which suggests that time outdoors can improve attention and reduce hyperactivity (Ruiz-Gallardo et al., 2013; Amoly et al., 2014; Flouri et al., 2014; Moore et al., 2016; Kuo et al., 2018). Our qualitative results show some evidence of each of these explanations, as some teachers expressed surprise at how engaged ECBD students were outdoors; others seemed to transform how they viewed behavior as appropriate or not; and others reported changes in the students themselves. Although teacher perceptions may have shifted rather than actual student attention and behavior, this perception shift is beneficial. Teacher perceptions can influence academic achievement well-into a student's future (Alvidrez and Weinstein, 1999; Sorhagen, 2013; Baker et al., 2015), and a shift in perceptions around student attention and behavior outdoors may reduce any apprehensions around outdoor instruction. We did not find treatment effects associated with classroom attention and behavior, but future research should continue to examine the possibility that our findings may transfer to impacts in the classroom. As recent research finds increased classroom engagement after lessons in nature (Kuo et al., 2018), future research may find similar trends among with ECBD, particularly with a larger sample size than our study. We suggest further research that replicates this study include more objective measures of student attention and behavior to further identify ways in which outdoor instruction may relate to ECBD student attention and behavior in the outdoors and in the classroom.

In addition to addressing indicators of ECBD, teachers should consider outdoor EE a viable instructional strategy for science teaching, as it appears as least as effective in supporting science learning for students with ECBD than traditional science instruction. Elementary school teachers often feel challenged to differentiate their instruction in classrooms that include 
students with a range of academic and behavioral strengths, and these challenges are often exacerbated when teaching science (Southerland and Gess-Newsome, 1999; Tobin and Tippet, 2014). Opportunely, other studies have demonstrated that outdoor EE has led to gains in science knowledge for all students (Jon Schneller et al., 2015; Wells et al., 2015). In our study, those findings seem to hold true for ECBD students specifically, suggesting outdoor EE can help teachers supplement science instruction for all students using a single approach. Additionally, outdoor EE has been shown to positively impact science interest and efficacy (Mohr-schroeder et al., 2012; Hiller and Kitsantas, 2014; Dettweiler et al., 2015). As nature of science, science efficacy and science grades appeared to remain stable in both treatment and control groups, outdoor EE instruction appears just as effective for students with ECBDs as classroom instruction in maintaining these measures. Since educators may cite concerns that outdoor EE may take away from instructional time (Carrier et al., 2014), these results are particularly encouraging. Instead of taking away from instructional time, outdoor EE seems to contribute to sustaining science efficacy and performance, even at an age when interest in science tends to wane (Cheung, 2009). Although some teachers are not aware that outdoor EE is effective (Ernst, 2007), it can be as rigorous and effective as indoor instruction and has potential to improve test scores (Volk and Cheak, 2003; Danforth, 2005; State Education and Environment Roundtable (SEER), 2005; McFarland et al., 2013). Future research is needed that focuses on students with ECBD to compare their progress with that of their peers when students experience more frequent outdoor EE. Additionally, as all data were self-reported, there are potential biases both from teachers and students. The researchers attempted to lessen this bias by not disclosing the specific details of this research apart from the larger program evaluation. However, teachers' perceptions of factors beyond our control, such as the outdoors as a learning environment, could have influenced ratings of attention and behavior (Pas and Bradshaw, 2014).

We suggest future research continue to explore outdoor EE as a teaching opportunity to engage students with ECBD. There are a host of benefits for students learning in nature, from improved classroom engagement (Kuo et al., 2018) to decreasing hyperactivity and inattention (Faber Taylor and Kuo, 2011; Moore et al., 2016). The bulk of this research centers on indicators of ECBD (e.g., attention and behavior), and our results align with findings suggesting that time outdoors can mitigate these indicators. In this study, repeated outdoor, science-based EE not

\section{REFERENCES}

108th Congress (2004). Individuals with Disabilities Education Act of 2004. Washington, DC: 108th Congress.

Alexander, K., Salmon, R. G., and Alexander, F. K. (2015). Financing Public Schools: Theory, Policy, and Practice. New York, NY: Routledge.

Alvidrez, J., and Weinstein, R. S. (1999). Early teacher perceptions and later student academic achievement. J. Educ. Psychol. 91, 731-746.

Amoly, E., Dadvand, P., Forns, J., López-Vicente, M., Basagaña, X., Julvez, J., et al. (2014). Green and blue spaces and behavioral development in only appears to decrease indicators of ECBD, but it also facilitates science learning on par with classroom techniques. Previous literature suggests outdoor EE can have similar impacts on all students, and our study indicates that these findings could extend specifically to those with ECBD. As the number of students with ECBDs continues to increase, teachers need creative solutions to instruct these students. We suggest outdoor EE that is repeated throughout the school year and aligned with standards may prove an invaluable tool to enhance science instruction for all students and, specifically, to reach those identified as ECBD.

\section{ETHICS STATEMENT}

The protocol was approved as exempt from the ethics review process by the Institutional Review Board for the Protection of Human Subjects in Research of North Carolina State University (IRB Protocol \#6533). We provided teachers with a choice of using an active or passive informed consent form for students and parents, in accordance with the requirements of the school districts. Active consent required parent consent and student assent signatures, while passive consent required similar signatures if students and/or parents wanted to opt out of the study. Consent was obtained from all research participants and from the parents/legal guardians by the method chosen by the teachers/schools.

\section{AUTHOR CONTRIBUTIONS}

RS was involved in study design, quantitative data acquisition, data analysis, and manuscript writing. SC was involved in qualitative data acquisition, data analysis, and manuscript writing. KS was involved in study design, quantitative data analysis, and manuscript writing.

\section{FUNDING}

Funding was provided through Muddy Sneakers environmental education program.

\section{ACKNOWLEDGMENTS}

We appreciate the staff at Muddy Sneakers, their partner schools, field sites, and teachers and students who made this study possible. 1351-1358. doi: 10.1289/ehp.1408215

Ardoin, N. M., Bowers, A. W., Roth, N. W., and Holthuis, N. (2017). Environmental education and K-12 student outcomes: a review and analysis of research. J. Environ. Educ. 49, 1-17. doi: 10.1080/00958964.2017.1366155

Aydeniz, M., Cihak, D. F., Graham, S. C., and Retinger, L. (2012). Using inquirybased instruction for teaching science to students with learning disabilities. Int. J. Spec. Educ. 27, 189-206.

Baker, B., Farrie, D., Johnson, M., Luhm, T., and Sciarra, D. G. (2017). Is School Funding Fair? A National Report Card. 
Baker, B., Sciarra, D., and Farrie, D. (2012). Is School Funding Fair? A National Report Card.

Baker, C. N., Tichovolsky, M. H., Kupersmidt, J. B., Voegler-lee, M. E., and Arnold, D. H. (2015). Teacher (Mis) perceptions of preschoolers' academic skills : predictors and associations with longitudinal outcomes. J. Educ. Psychol. 107, 805-820. doi: 10.1037/edu0000008

Brown, J. S., Collins, A., and Duguid, P. (1989). Situated cognition the culture of learning. Educ. Res. 18, 32-42.

Carrier, S. J., Thomson, M. M., and Tugurian, L. P. (2014). Elementary science education in classrooms and outdoors: stakeholder views, gender, ethnicity, and testing. Int. J. Sci. Educ. 36, 2195-2220. doi: 10.1080/09500693.2014. 917342

Carrier, S. J., Tugurian, L. P., and Thomson, M. M. (2013). Elementary science indoors and out: teachers, time, and testing. Res. Sci. Educ. 43, 2059-2083. doi: 10.1007/s11165-012-9347-5

Cawley, J., Hayden, S., Cade, E., and Baker-Kroczynski, S. (2002). Including students with disabilities into the general education science classroom. Except. Child. 68, 423-436. doi: 10.1177/001440290206800401

Cheung, D. (2009). Students' attitudes toward chemistry lessons: The interaction effect between grade level and gender. Res. Sci. Educ. 39, 75-91. doi: $10.1007 /$ s11165-007-9075-4

Crawford, B. A. (2000). Embracing the essence of inquiry: New roles for science teachers. J. Res. Sci. Teach. 37, 916-937. doi: 10.1002/10982736(200011)37:9<916::AID-TEA4>3.0.CO;2-2

Danforth, P. (2005). An evaluation of the National Wildlife Federation's Schoolyard Habitat Program in the Houston Independent School District, thesis, Environmental Education, Integrated Curriculums and Academic Standards.

Department of Public Instruction (2015). North Carolina Essential Standards 3-5 Science. Raleigh, NC: Department of Public Instruction.

Dettweiler, U., Ünlü, A., Lauterbach, G., Becker, C., and Gschrey, B. (2015). Investigating the motivational behavior of pupils during outdoor science teaching within self-determination theory. Front. Psychol. 6:125. doi: $10.3389 /$ fpsyg.2015.00125

Doucette, P. A. (2004). Walk and Talk: an intervention for behaviorally challenged youths. Adolescence 39, 373-388.

Dyment, J. E. (2005). Green school grounds as sites for outdoor learning: barriers and opportunities. Int. Res. Geogr. Environ. Educ. 14, 28-45. doi: $10.1080 / 09500790508668328$

EPA, U. (2018). What is Environmental Education? Available online at: https:// www.epa.gov/education/what-environmental-education.

Ernst, J. (2007). Factors Associated With K-12 teachers' use of environment-based education. J. Environ. Educ. 38, 15-32. doi: 10.3200/JOEE.38.3.15-32

Ernst, J. (2009). Influences on US middle school teachers' use of environment-based education. Environ. Educ. Res. 15, 71-92. doi: $10.1080 / 13504620802710599$

Ernst, J., and Tornabene, L. (2012). Preservice early childhood educators' perceptions of outdoor settings as learning environments. Environ. Educ. Res. 18, 643-664. doi: 10.1080/13504622.2011.640749

Faber Taylor, A., and Kuo, F. E. M. (2011). Could exposure to everyday green spaces help treat adhd? Evidence from children's play settings. Appl. Psychol. 3, 281-303. doi: 10.1111/j.1758-0854.2011.01052.x

Fägerstam, E., and Blom, J. (2013). Learning biology and mathematics outdoors: effects and attitudes in a Swedish high school context. J. Adv. Educ. Outdoor Learn. 13, 56-75. doi: 10.1080/14729679.2011.647432

Farnham, M., and Mutrie, N. (2003). Research section: the potential benefits of outdoor development for children with special needs. Br. J. Special Educ. 24, 31-38. doi: 10.1111/1467-8527.00008

Finn, J. D. (1993). School Engagement \& Students at Risk. Washington, DC: National Center for Education Statistics.

Flouri, E., Midouhas, E., and Joshi, H. (2014). The role of urban neighbourhood green space in children's emotional and behavioural resilience. J. Environ. Psychol. 40, 179-186. doi: 10.1016/j.jenvp.2014.06.007

Fox, P., and Avramidis, E. (2003). An evaluation of an outdoor education programme for students with emotional and behavioural difficulties. Emotion. Behav. Difficul. 8, 267-283. doi: 10.1080/136327503005 07025

Friend, M., and Bursuck, W. D. (2002). Including Students with Special Needs: A Practical Guide for Classroom Teachers. Boston, MA: Pearson Education, Inc.
Haney, J. J., Wang, J., Keil, C., and Zoffel, J. (2007). Enhancing teachers' beliefs and practices through problem-based learning focused on pertinent issues of environmental health science. J. Environ. Educ. 38, 25-33. doi: 10.3200/JOEE.38.4.25-33

Hanna, G. (1995). Wilderness-related environmental outcomes of adventure and ecology education programming. J. Environ. Educ. 27, 21-32. doi: $10.1080 / 00958964.1995 .9941968$

Hiller, S. E., and Kitsantas, A. (2014). The effect of a horseshoe crab citizen science program on middle school student science performance and STEM career motivation. Sch. Sci. Math. 114, 302-311. doi: 10.1111/ssm.12081

Jon Schneller, A., Schofield, C. A., Frank, J., Hollister, E., and Mamuszka, L. (2015). A case study of indoor garden-based learning with hydroponics and aquaponics: evaluating pro-environmental knowledge, perception, and behavior change. Appl. Environ. Educ. Commun. 14, 256-265. doi: 10.1080/1533015X.2015.1109487

Kaldenberg, E. R., Watt, S. J., and Therrien, W. J. (2015). Reading instruction in science for students with learning disabilities: a meta-analysis. Learn. Disability Q. 38, 160-173. doi: 10.1177/0731948714550204

Kam, C.-M., Greenberg, M. T., and Kusché, C. A. (2004). Sustained effects of the PATHS curriculum on the social and psychological adjustment of children in special education. J. Emotion. Behav. Dis. 12, 66-78. doi: $10.1177 / 10634266040120020101$

Kellert, S. R. (1985). "Attitudes toward animals: age-related development among children," in Advances in Animal Welfare Science, eds M. W. Fox and L. D. Michley (Dordrecht: Springer), 43-60.

Kuo, F. E., Faber Taylor, A. (2004). A potential natural treatment for attentiondeficit/hyperactivity disorder: evidence from a national study. Am. J. Public Health 94, 1580-1586. doi: 10.2105/AJPH.94.9.1580

Kuo, M., Browning, M. H. E. M., and Penner, M. L. (2018). Do lessons in nature boost subsequent classroom engagement? Refueling Students in Flight. Front. Psychol. 8, 1-15. doi: 10.3389/fpsyg.2017.02253

Markevych, I., Tiesler, C. M., Fuertes, E., Romanos, M., Dadvand, P., Nieuwenhuijsen, M. J., et al. Heinrich, J. (2014). Access to urban green spaces and behavioural problems in children: results from the GINIplus and LISAplus studies. Environ. Int. 71, 29-35. doi: 10.1016/j.envint.2014.06.002

Mårtensson, F., Boldemann, C., Söderström, M., Blennow, M., Englund, J. E., and Grahn, P. (2009). Outdoor environmental assessment of attention promoting settings for preschool children. Health Place 15, 1149-1157. doi: 10.1016/j.healthplace.2009.07.002

McFarland, A. L., Glover, B. J., Waliczek, T. M., and Zajicek, J. M. (2013). The effectiveness of the national wildlife federation's schoolyard habitat program: fourth-grade students' standardized science test scores and science grades. Horttechnology, 23, 187-193.

Melber, L. (2004). Inquiry for everyone: authentic science experiences for students with special needs. Teach. Except. Child. Plus 1, n2.

Melber, L., and Brown, K. D. (2008). "Not like a regular science class": informal science education for students with disabilities. Clear. House J. Educ. Strategies Issues Ideas 82, 35-39. doi: 10.3200/TCHS.82.1.35-39

Mohr-schroeder, M. J., Miller, M., Little, D. L., Schooler, W., Jacson, C., Walcoot, B., et al. (2012). Developing middle school students interests in STEM via summer learning experiences : see blue STEM camp. Sch. Sci. Math. 114, 291-301. doi: 10.1111/ssm.12079

Moore, A., Lynn, K., and Thomas, A. K. (2016). Engaging students in science through a nature hike : a case of two students with ADHD. Am. J. Undergrad. Res. 13, 73-80.

National Center for Education Statistics (2017). Children and youth with disabilities, 1-5. doi: 10.1177/1049732312468063

North American Association for Environmental Education (2010). Guidelines for Excellence: Preparation \& Professional Development, ed L. Mann III. Washington, DC: NAAEE.

Pas, E. T., and Bradshaw, C. P. (2014). What affects teacher ratings of student behaviors? the potential influence of teachers perceptions of the school environment and experiences. Prev. Sci. 15, 940-950. doi: 10.1007/s11121-013-0432-4

Peoples, S. M., O'Dwyer, L. M., Shields, K. A., and Wang, Y. (2013). With hiccups and bumps: the development of a Rasch-based instrument to measure elementary students' understanding of the nature of science. J. Appl. Meas. 14, $57-78$. 
Peterson, K. M. (2011). Nature, Nurture, Knowledge: The Promise of Experiential Learning for Students with Special Needs (No. 3495792). Boston, MA: ProQuest LLC

Rickinson, M., Dillon, J., Teamey, K., Morris, M., Choi, M. Y., Sanders, D., et al. (2004). A Review of Research on Outdoor Learning. Shrewsuby: National Foundation for Educational Research and King's College London.

Rios, J. M., and Brewer, J. (2014). Outdoor education and science achievement. Appl. Environ. Educ. Commun. 13, 234-240. doi: 10.1080/1533015X.2015.975084

Ruiz-Gallardo, J.-R., Verde, A., and Valdés, A. (2013). Garden-based learning: an experience with "at risk" secondary education students. J. Environ. Educ. 44, 252-270. doi: 10.1080/00958964.2013.786669

Russell, G. D. (2016). Section 504 : Ensuring Equitable Services for All. Raleigh, NC.

Saribas, D., Teksoz, G., and Ertepinar, H. (2014). The relationship between environmental literacy and self-efficacy beliefs toward environmental education. Procedia Soc. Behav. Sci. 116, 3664-3668. doi: 10.1016/j.sbspro.2014.01.820

Sorhagen, N. S. (2013). Early teacher expectations disproportionately affect poor children's high school performance. J. Educ. Psychol. 105, 465-477. doi: $10.1037 / \mathrm{a} 0031754$

Southerland, S., and Gess-Newsome, J. (1999). Preservice teachers' views of inclusive science teachings as shaped by images of teaching, learning, and knowing. Sci. Educ. 83, 131-150.

State Education and Environment Roundtable (SEER) (2005). California Student Assessment Project Phase Two: The Effects of Environment-Based Education on Student Achievement. Poway, CA.

Tamir, P. (1991). Factors associated with the relationship between formal, informal, and nonformal science learning. J. Environ. Educ. 22, 34-42. doi: 10.1080/00958964.1991.9943052

Tobin, R., and Tippet, C. D. (2014). Possibilities and potential barriers learning to plan for differentiated instruction in elementary science. Int. J. Sci. Math. Educ. 12, 423-443. doi: 10.1007/s10763-013-9 $414-\mathrm{z}$
Unfried, A., Faber, M., Stanhope, D. S., and Wiebe, E. (2015). The development and validation of a measure of student attitudes toward science, technology, engineering, and math (S-STEM). J. Psychoeduc. Assess. 33, 662-639. doi: $10.1177 / 0734282915571160$

Van den Berg, A. E., van den Berg, C. G. (2011). A comparison of children with ADHD in a natural and built setting. Child Care Health Dev. 37, 430-439. doi: $10.1111 / j .1365-2214.2010 .01172 . x$

Volk, T. L., and Cheak, M. J. (2003). the effects of an environmental education program on students, parents, and community. J. Environ. Educ. 34, 12-25. doi: $10.1080 / 00958960309603483$

Wells, N. M. (2000). Effects of “ Greenness" on children's cognitive functioning. Environ. Behav. 32, 775-795. doi: 10.1177/00139160021972793

Wells, N. M., Myers, B. M., Todd, L. E., Barale, K., Gaolach, B., Ferenz, G., et al. (2015). The effects of school gardens on children's science knowledge: a randomized controlled trial of low-income elementary schools. Int. J. Sci. Educ. 37, 2858-2878. doi: 10.1080/09500693.2015.1112048

Zint, M., Kraemer, A., and Kolenic, G. (2014). Evaluating meaningful watershed educational experiences: an exploration into the effects on participating students' environmental stewardship characteristics and the relationships between these predictors of environmentally responsible behavior. Stud. Educ. Eval. 41, 4-17. doi: 10.1016/j.stueduc.2013.07.002

Conflict of Interest Statement: The authors declare that the research was conducted in the absence of any commercial or financial relationships that could be construed as a potential conflict of interest.

Copyright $\odot 2018$ Szczytko, Carrier and Stevenson. This is an open-access article distributed under the terms of the Creative Commons Attribution License (CC $B Y$ ). The use, distribution or reproduction in other forums is permitted, provided the original author(s) and the copyright owner are credited and that the original publication in this journal is cited, in accordance with accepted academic practice. No use, distribution or reproduction is permitted which does not comply with these terms. 